\title{
MEMBANGUN RUANG URBAN ALTERNATIF MELALUI PERFORMANCE ART
}

\author{
Surya Farid Sathotho \\ Indonesia Institute of the Art Yogyakarta, Indonesia \\ suryafarid@isi.ac.id
}

\begin{abstract}
Abstrak: Ruang diciptakan oleh perilaku subyek historis. Gagasan ini merujuk pada konteks ruang urban dengan makna ruang yang cair. Dinamisnya makna ruang menantang membuka kesempatan untuk menawarkan ide dan makna baru bagi ruang. Performance dan performativity sebagai suatu bentuk perilaku subjek historis memiliki kapasitas untuk menciptakan makna-makna ruang yang baru. Tulisan ini hendak membahas mengenai proses danimplikasi dari ruang baru yang tercipta dari aktifitas menggeser tempat pertunjukan Tari Ibu oleh Brilyan (2019). Metode yang digunakan dalam penelitian ini untuk menilai apakah suatu ruang dapat disebut sebagai ruang urban atau tidak adalah dengan teori Pierce tentang apa yang dia maksudkan sebagai logical interpretant dan penjelasan Schehner mengenai performativity. Kesimpulan yang dapat ditarik dari pembahasan ini adalah bahwasannya sangat mungkin bagi performance untuk memindahkan tempat dan ruang urban.
\end{abstract}

Kata kunci: ruang, urban, seni pertunjukan, performatifitas, tari

\begin{abstract}
Space is created by the action of the historical subject. This idea refers to the fluidity of urban space context meaning. Performance and performativity as a form of historical subject behavior have the capacity to offer a new definition of urban space. This paper will discuss the process and implications of the new space created by the activity of shifting the venue for Tari Ibu dance performance by Brilyan (2019). Pierce's theory about "logical interpretant" and Schehner's explanation of performativity were utilized to assess whether a space can be referred to as urban and non-urban space. The conclusion that can be drawn from this discussion is that it is very possible to create an alternative urban space through a performance art.
\end{abstract}

Key words: space, urban, performance art, performativity, dance

\section{Pendahuluan}

Daerah urban menjadi ruang geografis untuk kontestasi, di mana berbagai kelompok masyarakat dan/atau kelompok kepentingan mencari tempat mereka dan kemudian menetapkan tanda mereka sendiri melalui berbagai jenis simbol, budaya atau seni. Kajian baru-baru ini telah mengamati bahwa kawasan perkotaan bukan hanya ruang fisik, tetapi juga memiliki ruang sosial - tempat orang dapat berkumpul dan berinteraksi. Gagasan ini menjadi pijakan untuk menempatkan gagasan tentang bagaimana performance dapat menentukan ruang dengan menggeser tempat atau sebaliknya.

Gedung teater, bersama dengan bangunan lain dianggap di bidang apa yang disebut ruang urban (Franco, 2018), karena biasanya terletak di pusat kota, di mana kegiatan urban berlangsung. Tak perlu dikatakan, pertunjukan teater sebagian besar memang dilakukan di gedung-gedung. 
Meski terlalu disederhanakan; bahwa gedung teater serta pertunjukan teater dapat dikatakan adalah salah satu identitas masyarakat urban. Kita melihat dari dekat apa yang diyakini sebagai bagian dari kegiatan masyarakat urban dalam rutinitas sehari-hari di sekitar Taman Budaya Yogyakarta (TBY), di mana di kompleks ini, yang memiliki dua panggung proscenium dan satu amphitheatre/open air, ditambah dengan ruang pameran dan semua hal yang berkaitan dengan seni dan pusat budaya. Tidak dapat ditolak bahwasannya TBY adalah merupakan simbol masyarakat urban.

\section{Tinjauan Pustaka}

Sekitar 5 kilometer ke utara dari TBY, kurang lebih kegiatan yang sama juga berjalan di kampus ISI Yogyakarta, yang dalam arti tempat orang mungkin memiliki keraguan apakah tempat ini adalah bagian masyarakat urban atau tidak. Tetapi apabila menyangkut ruang, maka keraguan seperti ini perlu dipertanyakan, seperti yang telah disebutkan oleh de Certeu;

$[\mathrm{P}]$ lace refers to those operations that make its object ultimately reducible to a fix location, 'to the being there of something dead, [and to] the law of a place' where the stable and the "law of the "proper" rules. Place excludes the possibility of two things being in the same location... Space occurs as the effect produced by the operation that orient it, situated it, temporalize it, and make it function in a polyvalent way.' Thus space is created 'by the action of historical subject' (Patraka, 2003).

Penting untuk mengenali apa yang dimaksud dengan "subjek historis", atau dengan cara lain, bagian terpenting untuk menciptakan ruang seperti itu adalah subjek di mana tindakan terjadi alih-alih tempat itu sendiri. Lebih jauh, Schechner (2001) menyebutkan bahwa, "theater as performance need event, time and space."
Perlu digaris bawahi bagaimana ia menempatkan ruang daripada tempat pada bagan yang digambarkannya. Ruang lebih penting karena tempat mungkin muncul kemudian ketika ruang ada. Tempat per se menjadi tidak berarti tanpa kegiatan apa pun. Selanjutnya menurut de Certeu, "the opposition between 'place' and 'space' refer to 'two sorts of stories' or narratives about how meaning is made" (Patraka, 2003).

Diskusi dapat dimulai dengan pernyataan de Certeu tentang bagaimana performance menciptakan ruang. Eksperimentasi ataupun kajian tentang performance (teater) yang dilakukan secara non konvensional dapat dianggap telah ketinggalan jaman. Meski demikian ada begitu banyak kemungkinan yang berkaitan dengan performance.

Secara konvensional, pertunjukan teater terjadi dan menempati ruang di gedung teater. Pertunjukan teater selalu membutuhkan panggung (lihat Carlson \& Shafer, 1990) tetapi kemudian di masa sekarang ini, ada tren tertentu di seluruh dunia untuk menemukan ruang alternatif demi perkembangan teater itu sendiri. Salah satu tindakannya adalah memindahkan tempat pertunjukan dari gedung teater. Beberapa mungkin hanya keluar dari aturan dinding keempat dengan mengundang penonton untuk bergabung dengan pertunjukan di atas panggung, sementara yang lain memilih mengadakan pertunjukan di luar gedung, atau ke bagian lain dari kota yang dianggap sebagai pusat kegiatan perkotaan. Beberapa orang mengambil tindakan yang lebih ekstrim dengan membawa pertunjukan ke tempat yang dianggap desa. Pertanyaan penelitian yang kemudian muncul adalah; apakah semua aktivitas ini masih dianggap urban?

Sebagai bahan kajian adalah Mother's Dance karya Mathori Brilyan (2018). Pertunjukan ini merupakan ujian akhir untuk meraih gelar sarjana di jurusan teater, ISI 
Yogyakarta. Dalam hal ini, mungkin patut dipertanyakan untuk mengambil performance seperti itu sebagai studi kasus. Tetapi tidak perlu dikatakan, bukankah performance ini sangat urban oriented? Performance dirancang oleh dan untuk masyarakat urban dalam konteks ruang dan tempat. (Dirancang dan dibuat berdasar proses ilmiah di sebuah institut seni). Bahkan sebagian besar penonton juga merupakan mahasiswa.

\section{Metode}

Metode yang digunakan dalam penelitian ini untuk menilai apakah suatu ruang dapat disebut sebagai ruang urban atau tidak adalah dengan melalui logical interpretant dan performativity

Logical interpretant atau penafsiran logis melihat sesuatu sebagai sebuah tanda mental yang dapat diproduksi ulang dan merupakan sebuah perubahan kebiasaan (lihat Buchler, 1955). Cara lain untuk melihat apakah ruang yang dimaksud adalah ruang urban atau bukan, dapat dilihat dari performatifitas (performativity), yakni sebagai sebuah hasil dari konstruksi sosial (lihat Kreinath, Snoek \& Stausberg, 2006).

\section{Hasil dan Pembahasan}

Mother's Dance dilakukan di kompleks pemakaman tua yang dikenal sebagai Antaka Pura atau Istana Kematian. Cerita di balik adanya makam ini adalah tentang bagaimana seorang dalang, yang dikenal sebagai Kyai Panjang Mas bersama dengan para anggota niyogo (bahasa Jawa: penabuh gamelan) yang berada dibawah pimpinannya, dibunuh oleh Raja Amangkurat I (1619-1677) dari Mataram karena sang Raja menginginkan istri sang dalang, Nyai Malang. Kuburan ini dimaksudkan untuk mengubur dalang dengan anggota kelompoknya, tetapi tragisnya kemudian istrinya juga ikut bunuh diri (Brilyan, 2018).

Lokasi Antaka Pura untuk konteks saat ini bisa dianggap tidak jauh karena hanya kira-kira tiga belas kilometer arah tenggara dari pusat kota Yogyakarta yang sekarang. Tetapi pada kenyataannya, tempat tersebut cukup terpencil dan jelas bukan bagian dari tempat urban Yogyakarta. Terletak di sebuah bukit kecil, tempat ini telah ditinggalkan selama beberapa dekade sebelum ditemukan kembali. Bahkan bagi orang-orang sekitarnya, tempat tersebut hampir tidak ada dalam kegiatan kehidupan sehari-hari mereka. Hampir tidak ada orang di sekitar, melakukan kunjungan atau apapun kecuali pakuncen (bahasa Jawa: penjaga / pemegang kunci) kuburan. Beberapa penduduk setempat mengatakan bahwa terakhir kali mereka naik ke bukit lebih dari satu dekade yang lalu ketika mereka mengevakuasi diri terhadap ancaman tsunami selama gempa Yogyakarta 2006 (Brilyan, 2018). Hanya ada jalan kecil ke desa terdekat dan jalan berbatu ke halaman kuburan dan bahkan tidak ada jalan setapak menuju ke puncak bukit.

Pertunjukan dimulai pukul 17.00 WIB, dalam cuaca hujan di bulan Januari di tempat tanpa akses listrik. Dimulai dengan pembukaan di kaki bukit, sementara beberapa penonton sudah menunggu di jalan menuju bukit; kebanyakan dari mereka perlahan-lahan mengikuti para pemain berjalan ke atas. Sepanjang jalan, dua kemanak (alat musik dari kuningan berbentuk menyerupai pisang atau kentongan kecil) dimainkan secara terus menerus menyertai langkah-langkah lamban dari pasangan pria dan wanita yang memakai topeng yang dikawal oleh sekelompok pria yang semuanya mengenakan surjan dengan motif lurik (surjan adalah pakaian tradisional bagi lakilaki Jawa, sementara lurik merujuk pada pola tertentu kain yang biasanya dipakai 
oleh orang desa). Di dekat gerbang pemakaman, pakuncen berhenti untuk meminta izin pemilik tempat tersebut. Saat memasuki kompleks pemakaman, orangorang melepas alas kaki mereka. Semua orang bertelanjang kaki di dalam kompleks pemakaman, meskipun baik di luar maupun di dalam kompleks, kondisi tanahnya sama saja. Proses ini menunjukkan bagaimana di dalam konteks performance, tempat dan ruang yang profane berubah menjadi ruang yang sakral (Schehner, 2001).

Ruang terjadi sebagai efek yang dihasilkan oleh operasi yang mengorientasikannya, menempatkannya, mewaktukannya, dan membuatnya berfungsi dengan cara polivalen. Ruang kemudian tercipta oleh tindakan subjek historis. Merujuk gagasan ini sekali lagi, mampukah Mother's Dance menyampaikan gagasan de Certeu? Sebagai pertunjukkan, jelas bahwa Mother's Dance membutuhkan tempat yang dipilih sesuai dengan estetika dan alasan praktis. Seperti yang dikatakan de Certeu bahwasannya tidak mungkin ada pertunjukan lain yang dilakukan pada waktu yang sama di tempat yang sama, karena tidak ada kemungkinan untuk menaruh dua cangkir pada titik yang sama pada waktu yang bersamaan. Itulah pengertian de Certeu tentang konsep tempat. Akibatnya, pada saat yang sama, ruang terjadi karena tempat ditempati oleh sebuah performance, sebuah subjek historis.

Selanjutnya, apakah Mother's Dance menawarkan ruang urban baru? Mungkin terlalu disederhanakan, tetapi seperti yang disebutkan sebelumnya, seluruh proses disiapkan dan dirancang oleh orang yang dianggap sebagai bagian dari masyarakat urban. Jadi mengapa ruang yang dibuat tidak dianggap sebagai ruang urban?

Pierce (lihat Buchler, 1955) dapat menjelaskan bagaimana kedua gambar (2 dan 3) memiliki citra aural yang sama. Ketika orang-orang di kedua gambar menafsirkan tanda-tanda yang mereka hadapi berdasarkan intepretant yang sama yang menghasilkan ekspresi yang sama, sikap yang sama, dan pada akhirnya, kebiasaan yang sama terhadap situasi yang serupa.

Seperti yang ditunjukkan pada gambar 2 dan 3, pada dasarnya tidak terlihat situasi yang berbeda dari dua gambar yang berbeda tersebut. Gambar 2 adalah gambar yang diambil dari Urban Culture Festival di Surabaya, sementara gambar 3 diambil dari pertunjukan Tari Ibu. Dalam pengertian Schechner, dapat dikatakan bahwa gambar 3 adalah "perempuan" (urban) karena mereka "memakai pakaian yang sama" sebagai penonton pada gambar 2 .

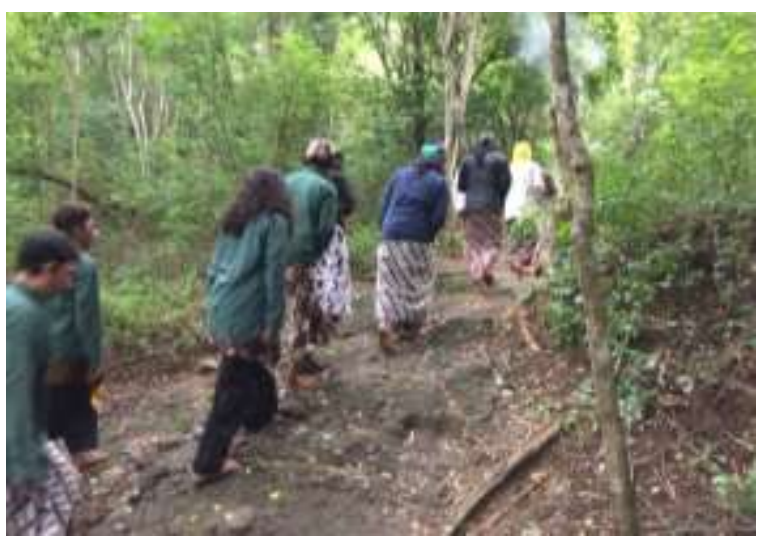

gambar 1. jalan setapak menuju puncak.

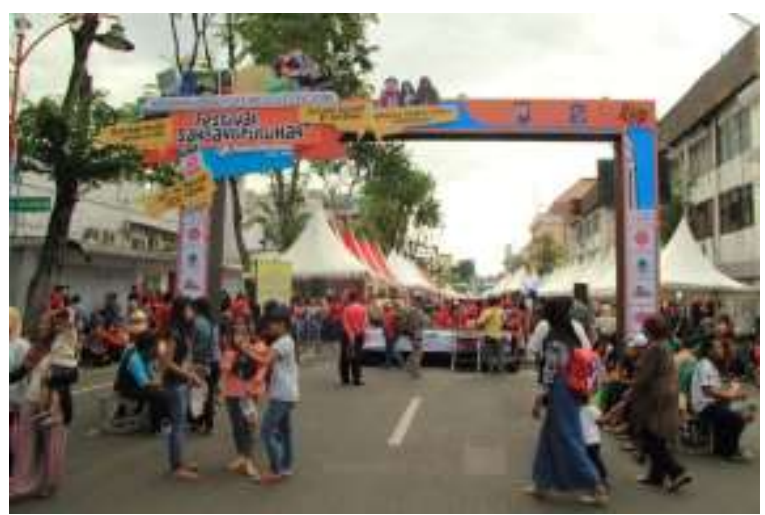

gambar 2. Penonton pada Surabaya Urban Culture Festival 2016 


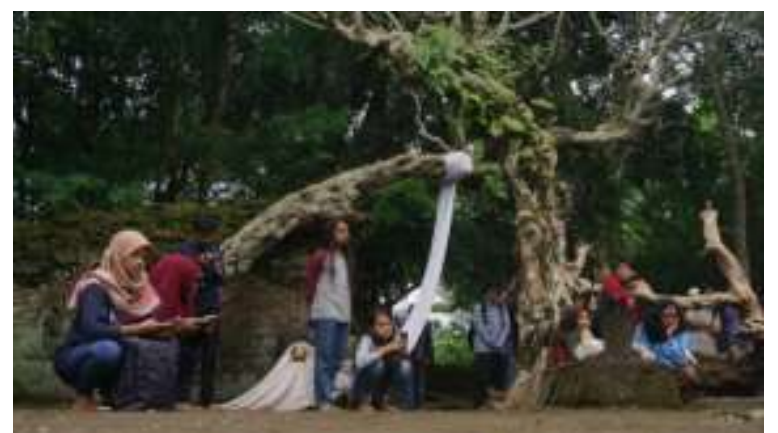

gambar 3. Penonton Mother's Dance

\section{Simpulan}

Ide tentang bagaimana kita dapat menciptakan ruang dengan memindahkan tempat adalah sesuatu yang perlu dipertimbangkan dalam merancang sebuah performance tertentu, karena urban dalam konteks ruang yang cair dan sifat cairnya menantang setiap subjek untuk menawarkan ide baru dari ruang tersebut. Perpindahan performance juga dapat berarti memindahkan semua kandungan performance ke tempat dan ruang yang benar-benar baru. Perpindahan yang dimaksud dalam makna konteks fisik dan ideologis.

Keberadaan ruang perkotaan baru mungkin terlihat dalam performance tertentu seperti yang terlihat di ruang urban "biasa". Pertama sebagai produk masyarakat perkotaan berdasarkan fakta bahwa orang yang menciptakan dan menikmatinya adalah bagian dari masyarakat perkotaan. Kedua, logical interpretant menunjukkan bagaimana orang-orang bertindak dengan cara yang sama, sekali lagi, dengan membandingkan dua gambar yang berbeda dari dua peristiwa yang berbeda. Performativity Mother's Dance sangat jelas pada bagaimana orang bertindak selama pertunjukan dibandingkan dengan acara lain yang diberi label Urban Culture Festival.

Sangat menarik untuk melihat bagaimana kondisi tempat (lihat gambar 1) sama sekali tidak dekat dengan tempat yang dianggap sebagai perkotaan tetapi tetap memberikan dampak yang sama terhadap penduduknya. Kesimpulan yang dapat ditarik dari pembahasan ini adalah bahwasannya sangat mungkin bagi performance untuk memindahkan tempat dan ruang urban.

\section{Daftar Pustaka}

Brilyan, M. (2018). Pertunjukan Mother's Dance, Berdasar Pada Ingatan Empiris dari Kisah Cinta dan Kematian Kanjeng Ratu Malang. Yogyakarta: skripsi, tidak diterbitkan.

Buchler, J. (1955). Philosophical Writing of Pierce. New York: Dover Publication.

Carlson, M. \& Shafer, Y. (1990). The Play's The Thing: an Introduction to Theatre. New York: Longman.

Kreinath, J., Snoek, J. \& Stausberg, M. (eds). (2006). Theorizing Rituals: Issues, Topics, Approaches, Concepts. London: Brill.

Schechner, R (Ed.). (2001). By Means of Performance, Intercultural Studies of Theatre and Ritual. USA: Cambridge. 